\title{
Atenção hospitalar: um espaço produtor do cuidado integral em saúde
}

\author{
Hospital care: a space in integral health care producer
}

\author{
Heloísa Helena da Silva Guedes* \\ Marina Monteiro de Castro e Castro*
}

\begin{abstract}
Resumo:
O presente artigo é uma revisão bibliográfica que parte da compreensão de que a produção do cuidado integral em saúde aponta questões que extravasam a competência técnico-científica em que se baseia o modelo biomédico que tem sido historicamente o grande estruturador das ações em saúde. Destacamos que quando tratamos da produção do cuidado no espaço hospitalar temos por base um referencial que trata a abordagem ampliada do problema de saúde e de suas determinações a partir do cotidiano dos usuários, e de ações em saúde que primem pela problematização do processo saúde-doença através da educação em saúde.
\end{abstract}

Palavras-chave: Atenção hospitalar; Cuidado em saúde; Educação em saúde.

\begin{abstract}
:
This article is a review that part of the understanding that the production of full health care issues suggests that beyond the technical and scientific expertise on which the biomedical model that has historically been the major structures of the shares in health. We stress that when we deal with the production of hospital care in the area have been based on a benchmark approach that addresses the larger problem of health and its determination from the daily life of users, and stock health that pressed by the problematization of the health-disease through health education.
\end{abstract}

Key-words: Hospital Care; Health care; Health education

\section{Introdução}

A saúde em seu conceito ampliado, definido como resultante dos determinantes sociais para além dos aportes biológicos, exige a construção de uma rede de cuidado que trabalhe sob o prisma da produção da saúde enquanto qualidade de vida e não a partir do viés da doença. Essa rede de cuidado pode ser traduzida como a rede de serviços de

\footnotetext{
* Assistente Social do INSS- Juiz de Fora. Mestranda em Serviço Social -Universidade Federal de Juiz de Fora (UFJF).formanda2002@yahoo.com.br

** Professora substituta da Faculdade de Serviço Social - Universidade Federal de Juiz de Fora (UFJF). Mestre em Serviço Social-UFJF. marinamccastro@yahoo.com.br
} 
saúde que, dentro do princípio-diretriz da descentralização do Sistema Único de saúde (SUS), deve ser regionalizada e hierarquizada através da atenção básica, intermediária, média e alta complexidade.

Nesta conformação dos serviços de saúde, apregoada pela Política de Saúde brasileira em seu período universalista, elege-se como atenção básica as Unidades e Postos de Saúde; unidade intermediária as clínicas de especialidades; média e alta complexidade os hospitais. Tais serviços, ainda que sejam estruturados de forma hierárquica, guardam profunda relação entre si, conformando a intersetorialidade, sendo acionados ou referendados com dada freqüência de acordo com o fluxo da demanda.

Para garantir um atendimento de qualidade e responsivo, os serviços, resguardadas as suas especificidades e capacidade instalada, devem ser resolutivos a tal ponto que não quebrem a linha do cuidado, garantindo uma assistência integral à saúde. Segundo Franco e Magalhães Jr.(2003, p.05)

\begin{abstract}
A proposta pensada para vencer os desafios de ter uma assistência integral à saúde,começa pela reorganização dos processos de trabalho [...] e vai somandose a todas outras ações assistenciais, seguindo aquilo que nos diz CECÍLIO \& MERHY: “... uma complexa trama de atos, de procedimentos, de fluxos, de rotinas, de saberes, num processo dialético de complementação, mas também de disputa, vão compondo o que entendemos como cuidado em saúde. A maior ou menor integralidade da atenção recebida resulta, em boa medida, da forma como se articulam as práticas dos trabalhadores [...]".
\end{abstract}

Tomando-se o pensamento dos autores ao apontar que o maior ou menor grau de integralidade alcançada na atenção disponibilizada advém do modo como se dá a interface entre as ações dos profissionais de saúde, completamos que avançar ou não na integralidade remete-nos, também, à questão do modelo de atenção operacionalizado nos serviços - se médico-centrado ou usuário-centrado. Um modelo usuário-centrado prevê a responsabilização no cuidado a este indivíduo portador de direitos, logo, um serviço responsivo e resolutivo demanda não só o conhecimento técnico-científico, recursos materiais, mas, também, também o acolhimento e vínculo que gera um encontro entre sujeitos e não entre objetos.

Defendendo um cuidado de fato integral, acolhedor das demandas e propiciador de autonomia dos sujeitos envolvidos na ação, há que se pensar em serviços de saúde que tenham potencial de investimento na melhoria da qualidade de vida dos sujeitos. Comumente, pensa-se a atenção básica como território de oportunidades de ações mais 
abrangentes como visitas domiciliares, grupos educativos, salas de espera, campanhas de todas as ordens, deixando aos serviços especializados e de média e alta complexidade a alcunha de espaços para tratamento e cura de doenças, sem muita aptidão para o exercício da fala e da escuta, para a relação mais próxima entre profissional e usuário.

$\mathrm{Na}$ contramão desse pensamento, salientamos que todos os níveis de atenção guardam possibilidades salutares de promoção da saúde enquanto qualidade de vida e direito do cidadão; logo, ainda que culturalmente pensemos o hospital como a instituição que incuba a doença, neste artigo buscaremos evidenciar para o leitor as potencialidades do espaço hospitalar como produtor do cuidado, enfocando a educação em saúde como uma possibilidade de efetivação do olhar cuidador.

\section{Média e Alta Complexidade: Terreno Fértil para Múltiplas Práticas}

Quando se pensa a respeito dos hospitais, como setor de média e alta complexidade na área da saúde, não raro reporta-se à idéia de um serviço complexo cuja prática profissional é distante dos moldes de humanização/integração profissional-usuário. Segundo Rollo (1997), percebe-se o hospital como locus da combinação excesso de demanda com ociosidade, onde falta tudo desde recursos humanos e materiais à compreensão ampla de saúde como direito daqueles que necessitam de cuidados hospitalares.

Contudo, o que nos coloca este autor - no que concorda-se plenamente - é que os hospitais podem vir a ser importantes instituições na garantia da equidade, integralidade da assistência e na defesa da vida desde que as práticas desenvolvidas estejam comprometidas com algo maior, ligadas não apenas à questão biológica-curativista (de suma relevância) mas, também, com o universo da prevenção e promoção da saúde (SILVA, 2005).

O panorama atual, na análise elaborada por estudiosos e grupos progressistas ligados à saúde coletiva, tem possibilitado a incorporação de uma nova visão de assistência reorientando o processo de trabalho no setor de média e alta complexidade. Um exemplo prático de inversão de modelo no cuidar, é o que está ocorrendo no campo da psiquiatria com a redefinição da relação profissional/usuário/família/sociedade, sem falar do reordenamento no fazer das equipes multiprofissionais valorizando princípios como acolhimento, responsabilização, humanização e vínculo no trato terapêutico (SILVA, 2005). 
Independente da natureza da atenção hospitalar (se psiquiátrico, de ensino ou geral), o fato é que modelos de assistência centrados no paciente e na sua rede de relações, são terrenos férteis para um atendimento integral, universal, eqüitativo resguardando a pessoa humana em suas singularidades. De acordo com Campos (1994) os hospitais podem ser um espaço de realização profissional, para o exercício da criatividade, um local onde sentir-se útil contribua para despertar o sentido de pertinência à coletividade.

Segundo Oliveira (1997), a implantação de propostas inovadoras, pautadas na humanização, responsabilização, vínculo e demais formas que não sejam as puramente curativistas, apresentam diversas resistências, mas não são impossíveis. Dentro do modelo assistencial usuário-centrado, pode-se quebrar com a lógica dominante de verticalidade das ações, incentivando todos, desde profissionais à usuários, para o envolvimento no processo de prevenção, promoção, recuperação e cura. Limites e possibilidades são vislumbrados ao longo do incremento dessas práticas, que tendem a ser superados no cotidiano do processo de construção do trabalho coletivo em saúde.

Optar por um modelo de assistência usuário-centrado é cultivar nas instituições de saúde, espaços coletivos de problematização, delineamento de diretrizes, exercício da referência e contra-referência, escuta atenta do usuário, dentre outras. O que se pretende com esta postura ampla é

\footnotetext{
quebrar a dureza do hospital (rotinas decorrentes da institucionalização das pessoas), garantir o respeito dos usuários, resgatar o vínculo e a responsabilização dos profissionais e pacientes, propiciar respeito e dignidade no exercício das várias profissões que se concretizam no espaço chamado Hospital (OLIVEIRA, 1997, p. 346).
}

Como apontado, é possível pensar novas práticas no setor terciário a partir de um arcabouço teórico-metotológico que não seja curativista/biologicista, bastando reconhecer os usuários do sistema de saúde como sujeitos e humanizar as relações a partir das ações de:

a) Acolhimento: compreendendo a recepção do usuário desde a sua chegada, responsabilizando o profissional integralmente por ele, ouvindo sua queixa, permitindo que ele expresse suas preocupações e angústias. Ao mesmo tempo, devendo colocar os limites necessários, garantindo atenção resolutiva e a 
articulação com os outros serviços de saúde para continuidade da assistência. A proposta é que o serviço de saúde seja organizado de forma usuário-centrada (comprometido com a defesa da vida individual e coletiva), tendo em vista atender as pessoas que procuram os serviços de saúde, garantindo a acessibilidade universal; reorganizar o processo de trabalho, afim de que este desloque seu eixo central do médico para uma equipe multiprofissional (equipe de acolhimento), que se encarrega da escuta do usuário, comprometendo-se a resolver seu problema de saúde.

b) Humanização: através da valorização dos diferentes sujeitos implicados no processo de produção de saúde: usuários, trabalhadores e gestores; a identificação das necessidades sociais de saúde; a mudança nos modelos de atenção e gestão dos processos de trabalho tendo como foco as necessidades dos cidadãos e a produção de saúde; o compromisso com a melhoria das condições de trabalho e de atendimento e a troca e a construção de saberes; o trabalho em rede com equipes multiprofissionais.

São princípios básicos da Política de Humanização: a valorização da dimensão subjetiva e social em todas as práticas de atenção e gestão no SUS, fortalecendo o compromisso com os direitos do cidadão, destacando-se o respeito às questões de gênero, etnia, raça e orientação sexual; a construção de autonomia e protagonismo dos sujeitos coletivos implicados na rede do SUS; o fortalecimento do controle social com caráter participativo em todas as instâncias gestoras do SUS; e o compromisso com a democratização das relações de trabalho e valorização dos profissionais de saúde, estimulando processos de educação permanente.

c) Responsabilização e Vínculo: com a construção de equipes que sejam responsáveis pelo acompanhamento dos pacientes, elaborando plano terapêutico personalizado; a não fragmentando ações; o retorno do paciente para a mesma equipe; o olhar o cidadão doente como sujeito de seu processo de recuperação e cura, agilizando e qualificando a assistência, dando segurança aos usuários; e o envolvimento da família no processo de recuperação/cura. 
Entretanto, sabe-se que a implantação de práticas inovadoras não tomam seu lugar sem a correlação de forças dos sujeitos envolvidos, sem o embate e o estranhamento que o novo traz à rotina de um trabalho muitas vezes já alienado e viciado. Mas para ganhar status de qualidade e eficácia a assistência prestada nos serviços de saúde, em especial no hospital, deve se desvencilhar das amarras de um modelo tradicional que já não comporta as atuais necessidades humanas para investir em práticas que contemplem o conceito ampliado de saúde apregoado pela Reforma Sanitária e consolidado na Constituição de 1988 e nas leis que regulamentam a Política de Saúde no Brasil - 808090 e 814290 . Estas práticas visualizam o usuário como cidadão portador de necessidades biopsicosociais e culturais.

\section{O Hospital como Espaço de Realização do Cuidado em Saúde}

Carapinheiro (1998) aponta que o hospital ocupa um lugar no sistema de saúde que está intrinsecamente relacionado à própria posição do sistema de saúde na sociedade, pois se adaptam as mudanças políticas e econômicas. Porém, conserva uma definição que perpassa pela tomada de decisões sobre políticas médicas e hospitalares particulares.

O hospital repercute e traduz nas suas escolhas políticas, as orientações políticas gerais, e reflete, de acordo com a configuração própria de estrutura de poder, as relações de força entre os grupos detentores das principais formas de poder social, constituindo assim um espaço de ação de grupos, cujos fins, legitimidade e quadros de referência não se localizam apenas no hospital (CARAPINHEIRO, 1998, p.23).

O hospital é considerado pela mesma autora uma organização moderna e complexa, onde são ancorados processos sócio-históricos recentes e incorporado a noção moderna de serviço público, a produção do saber médico e a prática da medicina moderna, simbolizando o poder social da profissão médica e a institucionalização dos conhecimentos médicos especializados.

O hospital é um lugar altamente profissionalizado que reúne uma diversidade de profissionais que possuem formação e socialização profissional diferenciadas, que ocupam diferentes posições hierárquicas e diferentes espaços na divisão do trabalho. As profissões 
possuem também diferenciada maneira de compreender o processo saúde-doença o que desencadeia processos de negociação.

Nasser (2001) ressalta que os hospitais surgem embasados num modelo unifatorial da doença que é decorrente de uma visão clínica que tem como suporte o Relatório Flexner ${ }^{1}$. Esta lógica tem permeado as práticas de saúde nas instituições hospitalares, ficando estas a cargo do tratamento, cura e recuperação da doença de forma pura e simples.

A partir da década de 30 do século $X X$, houve um avanço no que se refere à visão multi-causal do processo saúde-doença e a incorporação de outras profissões, mas esta se deu de forma tímida.

Do pós-guerra até meados dos anos 80 do mesmo século, houve uma ampliação da complexidade e especialização dos hospitais em departamentos, serviços e unidades, permitindo o aprofundamento do conhecimento específico, dificultando o entendimento da totalidade e desconsiderando o homem como determinado por relações afetivas, experiência de vida e como parte de uma totalidade social (PIRES, 1998).

Assim, de acordo com Carapinheiro (1998) o hospital apresenta traços estruturais que caracterizam instituições totalitárias,

Com o isolamento do doente em relação ao mundo exterior, a promiscuidade na organização do agrupamento físico dos doentes, o cumprimento de um regulamento hospitalar que programa a sua vida quotidiana e a apreciação dos comportamentos dos doentes a partir da referência única a uma ideologia centrada na doença/cura (CARAPINHEIRO, 1998, p.56).

O processo de admissão do paciente acaba sendo entendido como um conjunto de procedimentos e operações que reduzem a pessoa a doente.

Nota-se as formalidades da chegada ao hospital e ao setor de internamento, o despojo das roupas e valores pessoais, a atribuição de uma cama e a obrigatoriedade de a ocupar imediatamente, a circulação das papeletas e pastas onde passa a ser registrada uma outra biografia, a biografia de um homem doente. Neste processo, clarifica-se que o hospital aceitou o doente segundo os seus próprios termos, que o vai tratar como uma pessoa sem competência para o fazer e que espera que o doente se submeta às regras e aos regulamentos da instituição e ás decisões dos vários especialistas (CARAPINHEIRO, 1998, p.56).

1 Relatório publicado em 1910 pela Fundação Carnegie que consolida o paradigma flexneriano de atenção à saúde. Este se fundamenta no biologismo, individualismo, especialização, tecnificação e curativismo (Mendes, 1998, p.238-239). 
O serviço hospitalar é uma unidade de produção de cuidados médicos que reúne profissionais, saberes, tecnologias e infra-estruturas materiais. Os cuidados fornecidos aos pacientes seguem a linha tradicional que ressalta o desenvolvimento da medicina com disponibilidade técnica e científica no controle das doenças até o limite da cura. A submissão do paciente ao médico é justificada pela necessidade de tomada de decisões de cura para prevenir a morte. Assim, as relações terapêuticas são episódicas e se desenvolvem dentro do contexto de procedimentos necessários.

Cecílio (1997) coloca que é possível e necessário questionar os paradigmas hegemônicos a partir do hospital, pensando este de outra forma que não a que atualmente vista: hospital como último recurso a ser utilizado, o paciente como passivo diante da equipe, como corpo sobre o qual se realiza uma intervenção com a normatividade exclusiva da equipe de saúde, anônimo e sem rosto, sendo referido pela patologia que possui, tendo sua família classificada como "os que atrapalham a nossa rotina".

É preciso incorporar um olhar horizontal profissional/paciente, aproveitando o período de hospitalização para criar novas relações dos usuários com o sistema de saúde, reprogramar suas vidas, adquirir novos hábitos de autocuidado e autonomia, construindo o ambiente hospitalar como um espaço de promoção da saúde, de defesa da vida e da cidadania.

O curto tempo de permanência no hospital, pelo menos para a maioria das pessoas, é um tempo muito especial. Um tempo de fragilidade. Um tempo para repensar a vida. Um momento em que se depara de uma forma muito contrastada com o valor da autonomia e o que significa estar, mesmo que temporariamente, desprovido dela (CECíLIO, 1997, p.300).

Cecílio (1997) aponta ainda que é preciso batalhar no campo adversário para esta mudança de paradigma tendo em mente que o hospital é cidadela do poder médico e de seu projeto de sociedade; é um território virgem na perspectiva de humanização do atendimento e da defesa da vida; é um espaço possível de se pensar em promoção da saúde, educação em saúde e criação de vínculos; e o hospital não deve ser o espaço mais permanente ou definitivo de contato das pessoas com o sistema de saúde. 
Recuperando o pensamento de Rollo (1997), o autor relata que para a reconstrução das práticas assistenciais nos hospitais estas devem estar voltadas para a responsabilização e vínculo, abordagem do doente como cidadão sujeito do seu processo de recuperação, resolutividade, e integração do hospital com o sistema de saúde.

A responsabilização e o vínculo são colocados como fator fundamental, uma vez que nos hospitais os profissionais dedicam apenas $20 \%$ de seu tempo a atividades de contato direto com os pacientes e o processo de trabalho é organizado de forma seriada e centrado nos procedimentos, não havendo responsabilização pelo trabalho desenvolvido, nem construção de vínculo entre profissional/usuário.

Imaginem como melhora a relação de um doente com os profissionais, a partir do momento em que ele sabe que tem uma equipe determinada como responsável pelos seus cuidados durante o período de internação, que sabe o nome destas pessoas, que um servidor interage com ele em várias rotinas assistenciais, o quanto este contato melhora a capacidade de percepção da equipe em relação ao paciente e sua doença (ROLLO, 1997, p.326).

Os profissionais de saúde devem ver o doente como cidadão, como sujeito em seu processo de recuperação e cura, abordando-o de uma maneira integral que valorize sua subjetividade, percebendo-os como pessoas que possuem medos, sentimentos, que gostam de fala e ouvir, que julgam, possuem atitudes e potencialidades.

A abordagem ao paciente que é voltada apenas para a doença, diagnóstico e tratamento não vê outros determinantes do processo saúde-doença como o modo de vida, o contexto socioeconômico em que vive o paciente, o significado subjetivo e social do agravo que o acomete, e seu ânimo em recuperar e de ser sujeito do seu processo de cura.

Este tipo de prática contribui para a fragmentação, fetichização dos meios diagnósticos terapêuticos, aumento de custos, queda da eficácia das ações e falta de humanização das práticas profissionais com abordagem do sujeito doente como um objeto inerte e refém da equipe de saúde.

A resolutividade relaciona-se a disponibilização a todo cidadão, quando acometido por alguma enfermidade, o acesso a toda tecnologia existente. O hospital deve ser capaz de dar respostas efetivas aos agravos de saúde de seus usuários com resolutividade 
diagnóstica e terapêutica num tempo mínimo necessário que o caso exija, objetivando a eliminação ou diminuição do sofrimento e riscos, e promovendo a recuperação e a cura.

Por fim, deve-se procurar inverter a centralidade que os hospitais têm hoje no sistema de saúde, onde é visto como o vértice, o topo da pirâmide das unidades assistenciais. O objetivo é estabelecer uma relação de parceria e complementaridade, articulando os vários níveis de atenção á saúde.

De acordo com Alves (2005), o espaço hospitalar, tradicionalmente priorizador da formação médica e seguidor do modelo flexneriano, começa a demonstrar sinais de mudança na medida em que vem assumindo tarefas até então atribuídas às unidades de nível primário como as relacionadas à educação em saúde, ampliando sua missão e assistência.

Uma das formas de superação desta visão hegemônica da compreensão do processo saúde/doença no âmbito hospitalar é a realização da atenção em saúde voltada para a perspectiva do Cuidado.

O Cuidado no hospital possui natureza multidisciplinar, dependendo, assim, da articulação do trabalho de vários profissionais. O Cuidado é somatório de um grande número de pequenos Cuidados parciais que se complementam (e às vezes se dão de forma consciente e negociada), entre os diversos cuidadores que circulam e produzem a vida no hospital (CECÍLIO E MERHY, 2003). Uma complexa trama de atos, procedimentos, fluxos, rotinas e saberes, num processo dialético de complementação, mas também de disputa, compõem o que entendemos como cuidado em saúde (CECÍLIO E MERHY, 2003, p.198).

Qualquer intervenção hospitalar deve ter como ponto de partida o paciente e suas necessidades singulares, sustentada pela combinação entre tecnologia e humanização. $O$ Cuidado integral em saúde ocorrerá a partir da combinação entre as tecnologias duras, leve-duras e leves (MERHY, 2002).

O Cuidado hospitalar acontece dentro de um contexto de uma crescente racionalização das práticas hospitalares, onde há a decomposição do ato médico global em variados atos diagnósticos e terapêuticos que são desenvolvidos por trabalhadores diferentes. 
Basta imaginarmos os cuidados de um paciente com diabetes internado com um quadro de descompensação. Além dos cuidados iniciais do plantonista, que o recebe e interna a partir do pronto-socorro, ele receberá também cuidados da enfermagem, poderá ser visto, em algum momento, pelo cirurgião vascular, pelo cardiologista, pelo endocrinologista, pela nutricionista, pela assistente social e pela psicóloga (CECílIO E MERHY, 2003, p.198).

O hospital deve ser pensando como um importante espaço na construção do Cuidado em saúde, pois nele circulam variados tipos de pessoas, detentoras de diferentes necessidades, e em diferentes momentos de suas vidas singulares, que chegam ao serviço para serem atendidas de forma mais fragilizada. Assim, o espaço hospitalar deve ser necessariamente um local de realização do acolhimento, escuta, responsabilização e vínculo, constituindo um lugar estratégico para a realização do Cuidado em Saúde em seu sentido amplo.

Os hospitais encontram-se entre as organizações mais complexas que existem. Esta complexidade envolve a organização do trabalho, a necessidade de harmonizar o processo com o produto final desejado: promoção da saúde e bem estar e a coordenação das ações específicas de capa parte envolvida nas ações cotidianas do hospital.

A razão de ser dos hospitais se encontra nos espaços de interseção entre trabalhador de saúde e usuário que é o lócus primordial da formação da cadeia de significados sociais que formam a base das ações em saúde.

E a razão da existência de um hospital é Cuidar da Saúde da comunidade. Este Cuidar se dará sempre dentro de um campo de relações em que nem tudo é codificável e previsível, nem tudo pode ser respondido com técnicas objetivas e passíveis de se repetirem o tempo todo e da mesma maneira. Neste campo, estão presentes modos singulares de existência que requerem uma atenção especial às formas de execução do trabalho. Este trabalho possui natureza relacional e, portanto, integra os aspectos subjetivos de quem cuida e de quem é Cuidado.

[...] fortalecer este comportamento ético de articular o cuidado técnicocientífico, já construído, conhecido e dominado, com o cuidado que incorpora a necessidade de explorar e acolher o imprevisível, o incontrolável, o diferente e singular. Trata-se de um agir inspirado em uma disposição de acolher e de respeitar o outro como um ser autônomo e digno (BRASIL, 2002, s/p).

A dimensão cuidadora é um lugar privilegiado, pois questiona os limites e barreiras dos modelos hegemônicos que são focadas nos procedimentos e nas profissões de saúde. 
No manual do Curso de Capacitação de Humanização para os Hospitais (2004), Silva apresenta uma pesquisa feita em um hospital de Londres onde foi perguntado aos pacientes: O que é cuidado para você? Quando você se sente cuidado?

A autora identificou seis categorias que estão relacionadas à relação entre usuário/profissional e suas formas de comunicação:

1. "Cuidar é quando eu vejo que você é capaz de sorrir e sentir-se feliz no desempenho do seu trabalho";

2. "Cuidar é quando você me faz sentir seguro em suas mãos";

3. "Cuidar é quando você me faz sentir que também serei capaz de me virar, espero, quando chegar minha vez";

4. "Cuidar é quando você me faz sentir especial, embora eu seja como as outras pessoas são";

5. "Cuidar é quando você não me vê apenas como um moribundo, e assim me ajuda a viver";

6. "Cuidar é quando ouço minha família falar bem de você e sentir-se confortada na sua presença".

A primeira categoria se refere à escolha profissional. Se gostamos do que fazemos, com freqüência temos a comissura labial voltada para cima durante o desenvolvimento de seu trabalho, pois temos consciência de que estamos ali porque queremos e que o nosso papel, a nossa escolha foi o de ser cuidador.

Talvez os pacientes esperem por esse encontro, onde seja reafirmada, de maneira não verbal, essa nossa intenção de estar disponível e feliz por ser cuidador, estando prontos para dar o melhor de tanto para a recuperação quanto para a harmonização do encontro (BRASIL, 2004, s/p).

A segunda relaciona-se a segurança que se é transmitida ao paciente quando explicamos o que estamos fazendo, os passos do procedimento que será executado, quando nos identificamos através de um crachá e nos apresentamos dizendo o nome e o chamamos pelo nome.

O paciente não tem nenhuma obrigação de saber o tempo dos exames, o tempo dos procedimentos e as etapas necessárias para sua realização - essa linguagem é técnica. 
$\mathrm{Na}$ categoria de número três, os pacientes pedem para que não sejam tratados como crianças, quando não o são e que lembremos que não é porque estão doentes eles sofreram redução do quoeficiente de inteligência (QI).

\begin{abstract}
Muitas vezes usamos terminologias tipo: queridinho, mãezinha, tiazinha, quando eles podem se sentir diminuídos nessa situação, já que são adultos.

Todos que tomaram benzetacil, por exemplo, sabem que a mesma não é uma "picadinha" e que quando nos aproximamos com este medicamento e dizemos "agora é só uma picadinha", estamos tratando a pessoa como boba, porque ela vai sentir a inoculação da benzetacil, por, pelo menos, uns três a quatro dias (BRASIL, 2004, s/p).
\end{abstract}

No quarto momento, pode-se dizer que para alguém se sentir especial depende mais da disponibilidade, intenção e capacidade do profissional de saúde do que das condições financeiras e recursos materiais que ele possa dispor naquele momento.

Podemos fazer o paciente se sentir especial quando, mesmo, tendo apenas 30 segundos, nos aproximamos dele, sentamos ao seu lado e dizemos olhando em seus olhos "Eu só tenho 30 segundos, mas me conte como você está hoje". [...] Quando percebe nossa aproximação, mesmo com o tempo tão curto, ele se sente especial (BRASIL, 2004, s/p).

Na próxima categoria colocada, os pacientes solicitam que não sejam tratados como uma patologia e que sejam valorizados o que têm de positivo, independente do estado de saúde.

\footnotetext{
Isso ocorre, quando, por exemplo, não nos referimos ao paciente como a "gastrectomia do 43" ou como a "amputação do 15".

[...] Também valorizamos quando somos capazes de nos aproximarmos deles olhando, primeiro, para os seus rostos e depois para o soro, sonda ou dreno.

[...] Quando nos aproximamos olhando para isso e não para os seus rostos estamos dizendo que apenas cumprimos tarefas e que a tarefa é o nosso foco de interesse, e não eles, enquanto pessoas (BRASIL, 2004, s/p).
}

Na sexta e última categoria destaca da por Silva (2004), vê-se que não podemos cuidar de alguém isolado ou marginalizado de sua família, o que é fundamental a atenção que demos a ela, pois é, para o seu círculo que eles vão voltar, e essas pessoas são importantes para eles, pois os profissionais de saúde são transitórios.

Se a família se sentir segura com o nosso cuidado, isto será fundamental para que o paciente também se sinta seguro. Se a família valorizar os profissionais e sentir-se bem atendida, os seus comentários junto ao paciente o tranqüilizarão e o farão suportar as dores, procedimentos ou isolamento que porventura tenha que vir a passar (BRASIL, 2004, s/p). 
O Cuidar é muito mais do que um ato ou técnica. Cuidar é uma atitude, é a maneira como estamos diante do outro e como o compreendemos como ser humano e não somente como "ser doente". Cuidar representa a capacidade que temos de resgatar o nosso melhor lado, para fortalecê-lo naquilo que ele tem de mais saudável, bonito e que caracteriza a verdadeira relação humana.

Assim, de acordo com Ayres (2001), "Cuidar" da saúde de alguém vai além da construção de um objeto e da intervenção sobre ele. Para realização do Cuidado tem que haver a consideração e a construção de projetos, o estabelecimento de relação entre matéria e espírito, corpo e mente, não estando subordinadas as práticas parcelares de saúde. A atitude cuidadora deve expandir para a totalidade das reflexões e intervenções no campo da saúde.

Curar, tratar, controlar tornam-se posturas limitadas. Todas essas práticas supõem, no fundo, uma relação estática, individualizada e individualizante, objetificadora, enfim, dos sujeitos alvo de nossas intervenções. [...] Estamos falando de um norte prático, necessariamente técnico, mas também inexoravelmente ético, afetivo, estético. [...] Por isso, cuidar, no sentido de um "tratar que seja", que passa pelas competências e tarefas técnicas, mas não se restringe a elas, encarna mais ricamente que tratar, curar ou controlar aquilo que deve ser a tarefa prática da saúde coletiva (AYRES, 2001, p.70-71).

De acordo com o Programa de Humanização da Assistência Hospitalar (2002), a qualidade dos serviços prestados nos hospitais vai muito além do aprimoramento gerencial, aumento da eficácia e eficiência dos serviços ou aporte tecnológico. Há que se realizar o zelo pela qualidade do espaço intercessor (profissional-usuário), sem edificar uma ética para as relações de acolhimento e vínculo, e promovendo o respeito à dignidade humana. Sob este prisma, a metodologia de Educação em Saúde, que não possui sua inserção apenas no setor primário (mas pode e deve estar presente em todos os níveis de atenção) pode se configurar em um dos caminhos que o processo de trabalho em saúde deve adotar. 


\section{A Educação em Saúde como uma Possibilidade de Efetivação do Olhar Cuidador na Média e Alta Complexidade}

Em princípio, quando se debate a questão da Educação em Saúde, momentaneamente pode-se pensar que se problematizará Educação e Saúde como pólos sem nenhuma comunicação. Entretanto, estas duas áreas do conhecimento possuem interfaces, que fazem delas, importantes instrumentos de promoção da qualidade de vida.

Educar significa muito além do ensino formal. Educar relaciona-se ao ato ou efeito de educar e educar-se, numa relação dialética entre ensinar e aprender, visando a integração individual e coletiva do indivíduo em sociedade. A Saúde, nos remete aos determinantes da vida social, implicando trabalho, lazer, habitação, alimentação, educação, bem-estar, dentre outros, numa miríade de aspectos sócio-econômicos e políticos, podendo ser resumida - para além do aspecto biológico, do estar ou não sadio enquanto sinônimo de qualidade de vida. Assim, conjugando tais saberes, a Educação em Saúde nada mais é do que uma estratégia que norteia as ações no sentido de promover um cuidado integral, em que o usuário seja sujeito de seu processo saúde-doençacuidado.

Tendo como princípio norteador o exercício da fala e da escuta, onde se ensina, mas também se aprende, a Educação em Saúde pode ser considerada uma tecnologia relacional em saúde já que suas ações personificadas nas frentes de trabalho como grupo, atendimento individual, sala de espera, visita domiciliar, dentre outras, propõe que os serviços de saúde e suas múltiplas abordagens sejam entendidos como espaços de fluxos, demandas e necessidades dos usuários e não instâncias depositárias de saberes préconcebidos, carregados de conteúdo biologicista-mecanicista, higienista-comportamental, focados na doença e não na saúde.

Se o enfoque da Educação em Saúde hoje é privilegiar aspectos sociais para além dos biológicos, trazendo o usuário para a condição de sujeito e não de paciente/objeto, faz-se importante a adoção de práticas educativas que resgatem e levem em consideração a subjetividade do indivíduo, seu lugar na sociedade, sua percepção de mundo e de seu estado de saúde, sua rede de relações (família, comunidade), para que as ações de fato eduquem para a saúde, numa perspectiva dialógica/problematizadora, numa relação mais próxima entre serviços/profissionais/usuários/família. Deixar claro o objetivo a que se 
propõe com tais práticas, ou seja, a compreensão e promoção da saúde em suas múltiplas determinações, torna-se fulcral para essa nova concepção do educar (críticoemancipatória), para não recair no discurso tradicional da Educação em Saúde, de cunho ético-moral.

Distinguir bem estes dois modelos de Educação em Saúde - Tradicional e Crítico faz-se importante, pois, o incremento de práticas educativas em saúde sempre foi uma atividade tradicionalmente desenvolvida pelo Estado, visando promover comportamentos adequados para a prevenção e controle de doenças por meio da adesão popular (SILVA, 2005).

A Educação em Saúde foi marcada, originalmente, pelas doutrinas higienistas difundidas na Europa, no final do século XIX. A revolução bacteriana e a necessidade de se consolidar o Estado Burguês inspiraram uma concepção de educação higiênica, a qual marcou as instituições de saúde e de educação, visando ensinar certas práticas à população - incutindo-Ihe preceitos de saúde e normalidade do corpo e da mente (LUZ, apud ASSIS, 1998). A saúde era vista fundamentalmente como questão de bons hábitos, perdendo-se de vista seus determinantes sociais, políticos e econômicos (SILVA, 2005).

Nesta época, a educação em saúde caracterizava-se como estratégia de controle social, por parte das elites e do Estado, para adaptar os indivíduos à ordem vigente. Seu papel consistia na

[...] divulgação das normas de conduta moral, social e de higiene capazes de tornar os indivíduos mais propensos a aceitar suas condições de vida e trabalho e mais aptos a suportá-las (VILELA apud ASSIS, 1998, p.5).

Até a metade do século $X X$, o investimento do Estado na educação em saúde era vinculado aos interesses políticos e econômicos, como forma barata de se intervir no nível de doença e miséria da população, diminuindo as tensões sociais. Foi somente a partir do final da década de 50 do mesmo século que se vislumbrou a possibilidade de rompimento com a perspectiva adaptativa e controladora da educação em saúde, a partir do contato de profissionais de saúde com a experiência da Educação Popular, abrindo-se espaço para um novo tipo de pedagogia que não adaptativa, mas, integradora, não se restringindo mais a intervenção ao comportamento das pessoas. 
O período de 1958 a 1964 é visto hoje como a fase em que a educação popular se demonstrou mais política. O método Paulo Freire surgiu nessa época, baseado em uma filosofia de educação que recorre à conscientização política. Para além da redução ao aspecto estritamente pedagógico e marcado pela natureza política de seu pensamento, Freire, adverte-nos para a necessidade de assumirmos uma postura vigilante contra todas as práticas de desumanização. Para tal, o saber-fazer da auto-reflexão crítica e o saber-ser da sabedoria exercitados, permanentemente, podem nos ajudar a fazer a necessária leitura crítica das verdadeiras causas da degradação humana e da razão de ser do discurso fatalista da globalização (OLIVEIRA, 1997, p.12).

A concepção de Educação em Saúde, ao transitar do pólo Tradicional encaminhando-se ao pólo Crítico, passou a preconizar aspectos antes impensados, já que, pensar a Educação em Saúde sob a lógica emancipatória, é refletir sobre como as práticas educativas se dão à nível individual e coletivo. A tradicional Educação em Saúde caracteriza-se pela dicotomia entre o indivíduo e o coletivo, pelo caráter de transmissão de informações e potencialidades, pela definição restritiva de saúde (ausência de doença), por uma tendência de culpabilização dos indivíduos pela situação de adoecimento (ignorância como causa principal das patologias) e por uma idéia de "salvação" das instituições e dos técnicos (SILVA, 2005).

A Educação em Saúde enfatiza o aspecto político da educação como promotora de cidadania e transformação social. Enquanto nova concepção do educar, propõe uma práxis baseada em níveis de integração de dimensões múltiplas do ser humano, não sendo sinônimo de educação informal. A educação em saúde sob o prisma crítico abarcaria um processo que valoriza, sobretudo, os saberes e as práticas dos sujeitos. Como projeto pedagógico, preconiza a diversidade e heterogeneidade dos grupos sociais, as iniciativas dos educandos e o diálogo entre o saber popular e o saber científico (SILVA, 2005). Assim,

\footnotetext{
Busca trabalhar pedagogicamente o homem e os grupos envolvidos no processo de participação popular, fomentando formas coletivas de aprendizado e investigação de modo que promova o crescimento da capacidade de análise crítica sobre a realidade e o aperfeiçoamento das estratégias de luta e enfrentamento (VASCONCELOS, 2001, p.15).
}

Como apontado, a mudança na concepção de educar em saúde ocorre especialmente a partir dos anos 1960 e, tal perspectiva foi incorporada às propostas de 
ações em saúde a partir de então, tendo como fórum privilegiado o Movimento de Reforma Sanitária (final da década de 70) que defendeu a compreensão e produção da saúde enquanto qualidade de vida. Aprofundando o debate, a década de 80 do século XX foi um divisor de águas ao determinar na nova Constituição brasileira a configuração da Seguridade Social composta por um tripé: Saúde, Previdência Social e Assistência Social.

Com o advento da Constituição de 1988, começaram-se firmar os princípios da Reforma Sanitária de universalização e democratização da saúde, incluindo uma determinação social: o SUS (Sistema Único de Saúde) como universalidade, integralidade da atenção, equidade, direito à informação, incorporação do modelo epidemiológico, participação da população e descentralização político-administrativa, com mando único em cada esfera de governo. A partir desses princípios e diretrizes, os planos, programas e projetos implementados pelo Ministério da Saúde (MS) passou a adotar o enfoque crítico da Educação em Saúde como estratégia. No atual estágio do período universalista da saúde, as práticas educativas desenvolvidas nos serviços devem priorizar, dentre outras prerrogativas:

- $\quad$ a informação qualificada sobre o estado de saúde do usuário;

- a orientação amplo e acessível dos condicionantes do binômio saúde/doença;

- a utilização de tecnologias instrumentais de educação para publicização de informações/procedimentos (orientação individual e em grupos);

- $\quad$ a superação de formas de educação bancária (palestras e outras), assumindo posturas dialógicas;

- $\quad$ a co-responsabilização pelo processo de cuidado entre serviços-profissionaisusuários-família;

- $\quad$ a integração multiprofissional e interdisciplinar .

Considerada a saúde como processo histórico e social, o foco da intervenção não mais se centraria no comportamento individual, mas procuraria contemplar os próprios determinantes do processo saúde-doença tendo, como perspectiva, contribuir para ampliação das percepções das causas sociais, políticas e econômicas dos problemas da população usuária dos serviços de saúde. 
A intervenção tenderia a se encaminhar para a busca de soluções coletivas dos problemas de saúde, ou seja, contribuir de alguma maneira para a maior densidade das lutas sociais. Esse pode ser considerado o legado da educação e saúde: o que se deve saber para conquistar melhores condições de vida, passando a ser um processo de capacitação de indivíduos e de grupos para "a participação (crítica) das categorias de sujeitos subalternos para a organização do trabalho político que, passo a passo, abra caminho para a conquista de sua liberdade e de seus direitos" (VASCONCELOS, 2001, s/p).

Sob este aspecto, a educação em saúde é uma prática política que se propõe a contribuir para a formação da consciência crítica. Seu papel enquanto prática políticopedagógica é o de possibilitar uma concepção abrangente de saúde e, consequentemente, a promoção da saúde. A Promoção da Saúde é o objetivo que norteia a política pública de saúde brasileira e, promover saúde através das práticas educativas é capacitar os indivíduos e grupos para atuar na melhoria da sua qualidade de vida e saúde, requerendo uma maior participação no controle desse processo e incorporando preceitos como democracia, cidadania, responsabilização, acolhimento, vínculo, direitos e acesso.

O conceito de educação em saúde liga-se diretamente ao de promoção da saúde, pois abarca processos que visam não só a qualidade de vida daquela parcela dos indivíduos acometidos por algum risco social, mas, também, o bem-estar da população como um todo, reforçando o conceito ampliado de saúde que busca, dentre outros, preconizar aspectos comunitários, ambientais e sociais.

Ao se trabalhar de forma crítica o individual, a dimensão coletiva deixa de abarcar conceitos de naturalização do social, possibilitando ao indivíduo conceber com clareza o que o cerca. É na revalorização do diálogo que se pode estabelecer uma relação mais interativa entre saber popular e científico. Educar não é impor comportamentos à luz de nossas concepções, mas, possibilitar o encontro com o outro visando à construção de novos conhecimentos. Educar pressupõe a comunhão de diversos atores sociais (SILVA, 2005).

A linguagem, a comunicação franca e aberta, são um dos principais instrumentos para que o crescimento e interação mútuos aconteçam de fato. No agir comunicativo, a referência é uma comunicação livre, levando os sujeitos a abandonarem suas resistências para saber conjugar saber popular com saber técnico. Tendo em vista o exercício da fala e 
da escuta, a relação mais próxima entre técnicos e população, é que se poderá construir, nos serviços e ações, um espaço fecundo de comunicação e interação (SILVA, 2005).

A atenção universal, equânime e integral à saúde traz implícita, em sua concepção básica, um significado muito mais profundo que a simples reorganização e manutenção da rede de serviços de saúde. A melhoria qualitativa dos serviços ofertados, a democratização do conhecimento, a utilização de recursos humanos não especializados e de tecnologia simplificada e a participação da população na definição dos problemas de saúde e das prioridades e estratégias a serem implementadas, são pressupostos norteadores dessa nova filosofia sanitária: o saber como instrumento de exercício de direitos.

As atividades educativas visam aumentar qualitativamente o interesse, a vontade e o querer dos sujeitos para a mudança. O que se espera como resultado positivo destas ações é que elas possam causar nos indivíduos uma disposição para as transformações conscientes e necessárias - como fruto de uma abordagem crítica, reflexiva e que vá ao encontro das reais necessidades e expectativas individuais e coletivas. $\mathrm{O}$ grande desafio para uma atividade educativa em saúde é propiciar que todos os atores envolvidos saiam deste processo de uma forma positiva e diferente do que quando ingressaram, amadurecendo o saber acumulado, desconstruindo idéias pré-concebidas e construindo possibilidades para vivência da cidadania.

A educação em saúde apresenta vários desafios à sua completa absorção enquanto uma estratégia que privilegia uma relação dialógica. Para implementar ações educativas em saúde nos mais variados níveis de atenção e evitar posturas messiânicas ou autoritárias, algumas questões merecem ser objeto de reflexão: como está sendo aplicada esta estratégia? Até que ponto o trabalho realizado condiz com os interesses e necessidades dos usuários? Será que se está desencadeando a luta pela conquista de direitos político-sociais, visando a cidadania (cidadania esta versando, segundo Demo (1996), pela competência humana de fazer-se sujeito da história), ou será que se está direcionando e controlando as insatisfações dos usuários, enfraquecendo as iniciativas dos mesmos?

Dar respostas a tais inquietações só será possível através da leitura atenta e crítica da realidade a qual vivenciamos, desvencilhando-se a aparência, buscando a essência dos 
fatos. Ter clareza do projeto de intervenção que se quer desenvolver, é um passo importante para fortalecimento dessa estratégia dentro dos moldes emancipatórios aqui expostos; lembrando que a Educação em Saúde não é o único projeto pedagógico a valorizar a diversidade e heterogeneidade dos grupos sociais, a intercomunicação entre diferentes atores sociais, o compromisso com as classes subalternas, as iniciativas dos educandos e o diálogo entre saber popular e científico.

\section{Considerações Finais}

A amplitude e complexidade trazida pelo campo da saúde nos remete a necessidade de elaborarmos espaços de reflexão e atuação que articulem formas diferenciadas no trato das necessidades dos usuários. Merhy (2004) ressalta que o objeto central do trabalho em saúde, em seus diversos âmbitos, deve ser a produção do cuidado.

Quando tratamos do cuidado hospitalar ressaltamos que neste deve ocorrer uma combinação entre as tecnologias necessárias e a humanização, sendo o usuário abordado em suas necessidades singulares e em sua realidade. Esta atuação deve resultar na melhora e no prolongamento da vida, a partir da criação de um ambiente de conforto e segurança para a pessoa hospitalizada (CECÍLIO; MERHY, 2003).

Frente às reflexões, reforçamos a importância de se vislumbrar o hospital como pólo da saúde e não da doença; espaço para a operacionalização de um cuidado integral, humanizado que prime autonomia, dialogicidade, na liberdade, no poder de escolha do indivíduo.

O universo hospitalar, permeado por tecnologias leve-duras e duras também carrega a potencialidade de emprego de tecnologias leves, através práticas políticopedagógicas que possibilitem compreender a saúde como qualidade de vida.

Lançando um olhar para estas práticas, pode-se afirmar que há espaço para que vão além da doença em seu aspecto biológico/curativo. Entretanto, isso será possível devido à prática de um diálogo franco e aberto, na troca mútua entre profissionais e usuários. Há que se ter em mente que, este exercício de fala e escuta não se desenvolve automaticamente e, sim, à custa de um trabalho cotidiano de estímulo, pois, tanto o usuário deve ser trabalhado para externalizar seu saber, suas dúvidas e apreensões, quanto o profissional que deve se despir de sua postura de autoridade, de julgamento, 
para compreender a essência das demandas a ele colocadas e não apenas o superficial, o aparente. Essa disponibilidade para o aprendizado mútuo é um caminho percorrido no fazer cotidiano. Um caminho que tem um ponto de partida - que é a busca do conhecimento, da informação qualificada, da compreensão dos aspectos biopsicosociais, do interagir com o outro - é uma meta a ser atingida, como conquista da autonomia dos indivíduos.

\section{Referências}

ALVES, A. C. R. Reflexões sobre o processo de trabalho na área da saúde: o cotidiano das profissões na realidade do Hospital Universitário de Juiz de fora. Monografia (especialização em Saúde Coletiva). Juiz de Fora: UFJF, 2005.

ASSIS, M. Educação em saúde e qualidade de vida: para além dos modelos, a busca da comunicação. Estudos em Saúde Coletiva. n 169. Rio de Janeiro: UERJ, IMS, p. 3-30, 1998.

AYRES, J.R. Sujeito, intersubjetividade e práticas de saúde. Revista Ciência e Saúde Coletiva. Rio de Janeiro: v. 6, n. 1, p.63-72, 2001.

BRASIL. Curso de capacitação de humanização para os hospitais. Brasília: Ministério da Saúde, 2004.

2002.

. Programa Nacional de Humanização Hospitalar. Brasília: Ministério da Saúde,

CARAPINHEIRO, G. Saberes e Poderes no Hospital - uma sociologia dos serviços hospitalares. 3 ed. Porto: Ed. Afrontamento, 1998.

CECÍLIO, L. C.O desafio de qualificar o atendimento prestado pelos hospitais públicos. In: MERHY e ONOCKO. MERHY, E; ONOCKO, R (orgs). Agir em saúde: um desafio para o público. São Paulo: HUCITEC, p. 293-319, 1997.

. MERHY, E. E. A Integralidade do Cuidado como Eixo da Gestão Hospitalar. In: PINHEIRO, R.; MATTOS, R. A. Construção da Integralidade: cotidiano, saberes e práticas de saúde. 2 ed. Rio de Janeiro:UERJ, IMS: ABRASCO, p.197-210, 2003,

DEMO, P. Participação é conquista: noções de política social participativa. 3o ed. São Paulo: Cortez, 1996.

FLECK, M.P.A. O instrumento de avaliação de qualidade de vida da Organização Mundial de Saúde (WHOQOL-100): características e perspectivas. Ciência \& Saúde Coletiva, v.5, n1, p. 33-38, 2000.

FRANCO, T. B.; MAGALHÃES JÚNIOR, H. M. Integralidade na assistência à saúde: a organização das linhas do cuidado. In: MERHY, E.E et al (orgs). O trabalho em saúde: 
olhando e experenciando o SUS no cotidiano. Editora HUCITEC, São Paulo, p. 125-133, 2003.

MENDES, E. V. Uma agenda para a saúde. São Paulo: HUCITEC, 1998.

MERHY, Emerson Elias. Saúde: a cartografia do trabalho vivo. São Paulo: HUCITEC, 2002.

OLIVEIRA, E. C. Prefácio pedagogia da autonomia: saberes necessários à prática educativa. 60 ed. São Paulo: Paz e Terra, 1997.

OLIVEIRA, R. C. Assistência Hospitalar Pública em Betim: Mais um Passo em Defesa da Vida. MERHY, E; ONOCKO, R (orgs). Agir em Saúde: um desafio para o público. São Paulo: Hucitec, 1997.

PIRES, D. Reestruturação produtiva e Trabalho em saúde no Brasil. São Paulo:

Confederação nacional dos trabalhadores em seguridade social - CUT, Annablume, 1998.

ROLLO, A. A. É possível construir novas práticas assistenciais no Hospital público. In: MERHY e ONOCKO. In: MERHY, E; ONOCKO, R (orgs). Agir em saúde: um desafio para o público. São Paulo: HUCITEC, p. 321-352, 1997.

SILVA, H. H. Na mira da prevenção- DST/AIDS: uma experiência de Educação em Saúde no contexto do HU/UFJF. Monografia (especialização em Saúde Coletiva). Juiz de Fora: UFJF, 2005.

VASCONCELOS, E.M. (org.) A saúde nas palavras e nos gestos - Reflexões da Rede Educação Popular e Saúde. São Paulo: Hucitec, 2001.

Educação popular e a atenção à saúde da família. 2 ed.São Paulo: Hucitec, Sobral: Uva, 2001. 